\title{
4
}

\section{(DE)HABITUATION HISTORIES}

\author{
How to re-sensitize media historians
}

\author{
Andreas Fickers and Annie van den Oever
}

As Tom Gunning argues:

Every new technology has a utopian dimension that imagines a future radically transformed by the implications of the device or practice. The sinking of technology into a reified second nature indicates the relative failure of this transformation, its fitting back into the established grooves of power and exploitation. Herein lays the importance of the cultural archaeology of technology, the grasping again of the newness of old technologies.

(Gunning 2003, 56)

Newness is a transient phenomenon, a single phase in a longer history. David Park, Nicholas Jankowski and Steve Jones convincingly argue that the canon of media history focuses on the early periods of the histories of media, rather than the middle or late periods in their 'Introduction' to The Long History of New Media: Technology, Historiography, and Contextualizing Newness (2011). There is an obvious focus on media history's 'constitutive moments'. In a sense, media history “comes to us as a kind of prepackaged new media history" (Park et al. 2011). It is indeed worth stepping back from this for a moment, as they suggest, to "inquire about the role that newness plays in media, and in our histories of the media". There is a series of questions that comes to the fore: the epistemological questions about the over focus of media scholars on newness; the theoretical assumptions that guide them in this direction; and the critical, historiographical question "where are the histories of 'middle' and 'late' periods for media?" (Park et al. 2011).

This last question marks a serious problem in the field of media history: there is a notable gap in media historiographical research. The question then is: why are the middle and last phases missing? Is this due to a well-known, second problem in historiographical research: the tendency to create a linear if not teleological 
version of media history? As Andreas Fickers and Anne-Katrin Weber (2015) argued, on the one hand, "the diachronic perspective incorporates the inherent danger of producing linear or even teleological narratives, thereby neglecting the implicit openness of all historical development"; on the other hand, the "synchronic studies are confronted with the danger of overemphasizing the newness of specific historical events and in messing up the potentiality of history with its actual manifestations".

A third and significant problem in the field of media history is that media novelty is both over studied as well as undertheorized: conceptual constancy is lacking. The question then is: how to conceptualize the new (and renewal; and the "once new", as Tom Gunning labelled it in 2003). This question is even more pressing at this very point in time. Conceptual constancy is needed to elongate and synthesize the study of (new) media history. As Benjamin Peters stresses, "a conceptual constancy in the idea of novelty" is badly needed in a world of "torrential technological change" which causes "the near-instant obsolescence of studying new media": what is new on one day is obsolete the next (Peters 2009, 25).

In an attempt to reassess the 'new' in the term 'new media', Park and a range of contributors have sought to historicize and contextualize rather than theorize media newness. Their study reflects on a range of older (standard) studies on newness in media history by Lisa Gitelman, Carolyn Marvin, and others; they inspired a number of studies that have deepened the argument that the new and the novelty phase of media are overvalued in media studies and that an overfocus on newness is part of a rhetoric of the new in line with the marketing strategies of the industry institutionally framing new devices as something revolutionary if not utopian. The 'rhetoric of newness' has become such a characteristic feature of all media discourses that media scholars seem to have a hard time developing a critical distance from that trope (Fickers 2015). Paying attention to newness and 'revolutionary' developments has resulted in a bias in the field of Media and Communication Studies, as well as in Science and Technology Studies and in History of Technology. While processes of technological invention and innovation, as well as phenomena of re-mediation have been analysed in great detail, phenomena of hybridization, habitualization and routinization have received much less attention.

In the conclusions to his remarkable article on the 'new' in media studies, Peters $(2009,24-25)$ argues that it would be good to go against "the bulk of media history scholarship to treat only one period (usually the first) that a given medium appeared new". He wonders what a new media history conceptualized as a "renewable media history" might look like, suggesting "that the renewable quality of media presents a richer yet significantly underdeveloped framework for understanding media in history than is widely adopted" (ibid.). Thinking of media in terms of their renewability opens up new paths for media historians to look at media history, Peters claims: “(new) media history provides a set of lenses, such as the five stages of media renewability". Accordingly, he presents "a five-step cycle of new media evolution, from obscurity to obviousness and back again", arguing 
that new media can be understood as emerging technologies undergoing a historical process of contestation, negotiation, and institutionalization, and that "[ $\mathrm{t}]$ hese terms are meant to suggest ways to think through how media arc from social obscurity to invention, innovation, obviousness and obsolescence". In a similar fashion, Gabriele Balbi has proposed a four-step model, starting with a phase of imitation (when the new copies the old); specification (when the new becomes new); reconfiguration (when the old adapts the new); and, finally, co-existence (when the old and the new live together) (Balbi 2015, 231-249).

These proposals are valuable in several ways: as a reminder to media historians and historians of technology that - contrary to the industrial and institutional rhetoric - histories of media are cyclical rather than linear; as an attempt to refocus on such media cycles, and on the middle and last phases thereof, instead of focusing primarily, if not exclusively, on the newness phase; as a pointer at the different technical, cultural, legal, economic, and social powers in play in the history of media use, powers that need to be studied in their own terms. Instead of reproducing the evolutionary logic of linear (technical) improvement and enhancement, we aim to refocus our attention on the processes of 'naturalization' that so often fall under the radar of scholarly attention. When we become accustomed to 'new things', they are interwoven into the fabric of daily life (Nye 2006, 65). Leaving an innovation-centric view behind, we sympathize with David Edgerton's (2006) plea for looking at 'old' technologies in terms of their re-uses and alternative appropriations by offering a specific perspective that we find to be crucial to the understanding of past media practices: that is, the sensorial, perceptual, and experiential dimensions of media use. We want to show their relevance to understanding the individual and collective cultural appropriation and acceptation of media technologies. This article is a plea for a sensorial and tacit approach to media history aiming at a rethinking and a theorizing of media newness and media cycles from the perspective of the user experience.

\section{Sensorial dimensions in media history}

In the past, in joint as well as in separate papers, panels, and publications, ${ }^{1}$ we have focused on media use and media experiences to be included in the histories of media and technology; our plea was aimed at three specific things:

1. To take media objects from the glass cases of museums to help re-sensitize the researcher to past media objects and to create an awareness of the sensoperceptual and tacit traces left by media in practices of use;

2. To take the materiality of media technologies, as well as the sensorial and tacit dimensions of media use into account in the writing of the histories of media and technology; and

3. To question media history from the perspective of an experimental media archaeology by systematically reflecting upon the value and function of handson experiments and the methodology, protocol, and procedures used in such 
experiments, from simulations of practices of media use under the label of an experimental media archaeology to playfully recreating media experiences by tinkering/thinkering (Huhtamo) with media objects to re-sensitize the researcher, and reenactments to play on the historical imagination.

In line with our earlier work, we will take the material object - the technological device - and, more specifically, the sensorial and experiential dimensions expressed in media use as a point of departure for our reflections. Why would the sensorial and experiential dimensions of media use be a relevant point of departure for such reflections? And, by extension: why would such reflections help to theoretically frame media newness? The answer, as we will argue, is that the (media) technologies used for communication and information purposes work quite differently on users than, for instance, technologies of transportation. Media technologies stand out amongst the broad range of technologies used by humans, such as trains, aeroplanes, and elevators in as far as media technologies typically use representation as a means. As such, they affect users in a very specific way, quite different from trains and aeroplanes. Moreover, media technologies stand out among the media such as language because of their technical make-up, as Kittler has convincingly argued; for this reason, he labelled media technologies, somewhat tautologically as he would admit, 'technical media' (Winthrop-Young and Van den Oever, 2014).

We will first discuss the concept of 'technical media' to address the question of why and how media technologies require special treatment in both media and technology research in terms of the traces they leave in representation - with considerable implications for the user experience. Then, we will address the question as to why the sensorial effects created by technical media would typically be accompanied by a distinct experiential dimension and why this would help create the famous cyclical effects in the history of media use. Finally, we will discuss the implications for media historiographical research.

\section{The distortive effect of technical media}

In Gramophone, Film, Typewriter (1999), Friedrich Kittler introduced the notion of 'technical media' to discuss the specific material and technical make-up of media devices leaving specific traces in media use and needing attention when one studies (excavates) these processes. There were three main sources of inspiration for Kittler to start thinking along these lines: Michel Foucault and his archaeology of knowledge; thoughts on media as the message inspired by Marshall McLuhan (and Harrold Innis); and Rudolph Arnheim's studies of early film and visual perception from the early 1930 s onwards.

In his first book, Film as Art (Film als Kunst, 2006 [1932]), Arnheim famously discussed a crucial quality of film technologies: technically speaking, they produce a representation of the object, which resembles the object represented, yet they do so within the limits of the technology used. This particular line of thinking became a source of inspiration to Kittler, who responded to Arnheim at several places in 
Gramophone, Film, Typewriter. In Kittler's words, “(Technical] Media and [technical] media only fulfill the 'high standards' that (according to Rudolf Arnheim) we expect from 'reproductions' since the invention of photography" (Kittler 1999, 12). Here he quotes Arnheim on technical 'reproductions': “'They are not only supposed to resemble the object, but rather guarantee this resemblance by being, as it were, a product of the object in question, that is, by being mechanically produced by it [...]" (Kittler 1999, 12).

This, Kittler argues, implies a radical difference between 'technical media' and other communication media such as language. Whereas language operates by way of a "symbolic grid" that requires that all data "pass through the bottleneck of the signifier" (Kittler 1999, 4, 12), the 'technical media' process the physical effects of the real (Winthrop-Young 2011, 59; Winthrop-Young and Van den Oever 2014, 226-228). ${ }^{2}$

However, that is not all there is to it. Technological media, moreover, "operate against a background of noise [or blurs] because their data travel along physical channels; [. . .] According to Arnheim, that is the price they pay for delivering reproductions that are at the same time effects of the reproduced" (Kittler 1999, 45). Now let us reconsider within this context the Kittlerian dictum that "A reproduction [. . . ] refers to the bodily real, which of necessity escapes all symbolic grids" (Kittler 1999, 12). The problem is that in the process of production of data (to stick to Kittler's words), engineers and other technically oriented experts clearly identify the 'noise' and 'blurs' that are the by-product of the data traveling along the physical channels. Furthermore, it is clear that technical teams (e.g. engineers, projectionists and broadcasting teams) not only tend to identify such accidental byproducts of the production process as such, but also to propose technical amendments in line with the use of the medium as envisioned from the production/ distribution perspective, as documents indicate. ${ }^{3}$

The dynamic unfolding of invention testing/amendment is in itself a very interesting part of the dynamics in the history of technology, as well as the history of a medium (Turquety 2014). The user perspective, however, provides a remarkably different story. As abundantly shown in reception documents, users may well attribute meanings and emotions to traces made by the machine though they are made accidentally and without any intention. ${ }^{4}$ Viewers respond particularly strongly and often even with great excitement to 'distortions' in the visual representation of animated figures (Van den Oever 2011; 2013). Distortion is a generic term used by Arnheim for all types of (visual) distortions, be it disproportions, deviations, enlargement, deformation, decolorization, or fusion. Such distortions require attention in the study of media use as they affect users and leave traces in the perceptual process (Van den Oever and Tan 2014). From the start, Arnheim largely marked the limitations of the technologies as a positive thing. Seen from the perspective of the arts and aesthetics, the technical limitations came with a potentially huge advantage: expressive power. In the early essays assembled in Film as Art (2006 [1932]), Arnheim elaborately discussed the peculiarities created by the new film technologies during recording and projection, such as low-contrast, 
black-and-white images, 2D, and the numb world of the movies before the invention of sound in the cinema. Particularly the last feature Arnheim valued: cinema being silent as opposed to reality being full of sounds. The cinema's 'silence' almost automatically and inevitably moved film into the realm of the arts and aesthetics because these 'unrealities' (as Arnheim called them) come with the advantage of a notable impact on the user experience. They affect viewers.

Clearly, Arnheim, a perceptual psychologist, mainly focused on the expressivity of the image and the perceptual effects of the unrealities under discussion; unlike others, he did not focus as much on the powers unleashed by the machine itself. It was Kittler who put this topic of study on the research agenda by coining the term 'technical media' as part of his archaeology of the media. In addition to both Arnheim and Foucault, he developed a focus in research on the material, technical traces of media technologies, which needed to be excavated as they co-shape 'the message' (McLuhan) and the 'regimes' (Foucault). In Arnheimian terms, they create 'unrealities' that have an impact on the perceptual process. We propose labelling the distortions created by a technical medium technologyinstigated distortions as they constitute interesting aesthetic and perceptual categories in their own right.

\section{Technology-instigated distortions}

Technology-instigated distortions are interesting to artists, art historians, and philosophers of aesthetics - but why would they be of special interest to media historians, too? First, we assume that there is a direct connection between the technology-instigated distortions produced by novel (mimetic) media and their senso-perceptual and experiential impact on users, the so-called novelty experience. It is marked by an experience of a notable 'discontinuity' in the perceptual process: the process is deepened, complicated, and prolonged. Such effects are particularly well-known from first-time experiences with novel media (Van den Oever and Tan 2014). Psychologists speak about arousal symptoms that habituate. Here, in psychology, we find solid ground to theorize media novelty, hence to create the conceptual constancy needed for the field of media studies to speak about the 'new' in media history. Media newness can best be studied from the user perspective in terms of arousal symptoms in response to the use of novel (mimetic) media which trigger new/unfamiliar technology-instigated distortions which momentarily affect the user experience as a result of a discontinuity in the perceptual process. They are notable as they affect the user's (first-time) experience; and media historians have access to these because they are marked by users in reception documents (the distortions in the representations may be marked as 'new' or 'strange', etc.; the experiences as awesome or amusing or repulsive, etc.). If we know why novelty experiences appear (due to novel, technology-instigated distortions in the representation of people and things) and if we know how they express themselves in the user experience (in the notably deepened, prolonged perceptual process), then the question is: why do they disappear? 
In line with psychological studies, ${ }^{5}$ we assume, second, that the arousal symptoms disappear due to habituation; that is to say the effects on experience of the technology-instigated distortions of a novel medium are smoothened in the successive process of habituation (Van den Oever and Tan 2014). Clearly, the technologyinstigated distortions themselves do not just disappear - unless the technical medium is technically amended, e.g. by technicians. Interestingly, however, the effects of these distortions on the user experience do disappear in the process of repetitive exposure to a medium as perception becomes habitual (media habituation). Repetitive exposure - as is typical for the use of most (communication) media - creates so-called habituation effects which render the medium 'transparent'. That is the reason media become 'second nature' (Gunning 2003) so quickly and easily.

Following early perception studies, we assume that habituation/de-habituation cycles help constitute the cycles that seem so typical for media use. In "Art as Technique", Viktor Shklovsky spoke about the mechanisms of dehabituation and habituation respectively; these two key terms are often translated as de/automatization and de/familiarization. Though his discussion of these twin mechanisms misses psychological precision, we want to draw additional attention to it as part of our reflections on the experiential dimensions of de-habituation effects - to help researchers recognize references to related experiences in reception documents as typical for first-time and frequent users of media respectively. We assume that moments of so-called de-habituation are put in motion by novel media technologies at their moment of introduction; moreover, that such moments typically sensitize users to the novel technologies and, at least potentially, make them aware of the material, technical, and senso-perceptual make-up of the novel medium at hand. The sensitivity to the medium exists only momentarily and vanishes over time in the process of habituation. Van den Oever and Tan (2014) proposed calling such Sensitization Desensitization Cycles. Accordingly, we propose not to speak of Dehabituation Habituation Cycles but, more specifically, of Sensitization Desensitization Cycles. Additionally, we propose to discuss such phenomena as medium awareness and medium sensitivity, medium transparency, and media becoming 'second nature' in terms of such Sensitization Desensitization Cycles or SDCs, that is to say, in terms of an increase or decrease in sensitivity to a (technical) medium due to first-time or regular exposure to a (mimetic) medium respectively.

Furthermore, we assume that there is a close relationship between habituation effects and the appreciation for and adaptation of media used for communication and information purposes. The relationship (as we provisionally call it) requires further attention with the help of (media) psychology and perception studies to allow for an empirical testing of the habituation hypothesis and the precise effects on media users perceptually, cognitively, and emotionally. However, that is not the primary focus of our attention here. In line with our argument thus far, we assume that there is an interesting relationship between the SDCs as proposed here and the media cycles as proposed by Benjamin Peters. We assume that media cycles are only partly institutionally driven; and partly by user experiences shaping user practices (called 'user cascades' by Salehabadi 2016). Correspondingly, we propose 
a further conceptualization of media newness, with the help of (media) psychology to create the conceptual constancy needed to reconstruct not only the story of novelty experiences appearing and disappearing, but also the histories of 'middle' and 'late' periods of media as Park and others suggested.

This brings us to the topic of media researchers being desensitized to the material, sensorial, and tacit dimensions of their objects of study. Unsurprisingly, perhaps, 'media transparency' is at the root of most modern media theories as Lambert Wiesing (2014) has convincingly shown. Therefore, let us take a closer look at the predictable effects of Sensitization Desensitization Cycles on our field of study. First of all, we wonder whether new media researchers, sensitized to the "new media' of the 1990s, have helped to create an overfocus on newness in the field of media studies, if only because novelty experiences may well spur expert users no less than amateur users to distinct moments of sharpened medium awareness and experiences of awe, wonder, and astonishment, to use Gunning's favourite terms (Gunning 1995; 2003). Second, we wonder about the perhaps more important and more lasting effects on media research of routine exposure. The question is whether media researchers are not de-sensitized to most media, too, and have lost their medium awareness, by and large, just like the amateur users?

Being desensitized to a medium normally means that the sensitivity to the medium vanished as the initial arousal effects wear off due to habituation. This inevitably leads to a decrease in sensitivity to the distorting powers of the technology, to the point of users becoming almost fully insensitive to them. It may almost automatically lead to a point where the material presence of technologies in the perceptual process is no longer noted: a quick and swift shift in focus from the medium to the mediated becomes not only habitual, but even natural or 'second nature'. Being perceived as "natural" indicates that once the mechanism of habituation enhances such a smooth shift in the perceptual process from perceptual input to cognition, fully automatic and unnoticed by the percipients, they may altogether stop noticing the ontological difference between say a pipe in reality and one on a photo, TV, laptop, smartphone, cinema screen or canvas. This easily leads to an identification of the represented and the 'real thing'. As in the Magritte painting, one must remind the viewer: Ceci n'est pas une pipe [This is not a pipe] (The radical irony, of course, also includes the connotation of this painted pipe as overtly phallic).

In general, medium unawareness is a predictable and almost inevitable effect of habituation. Once media technologies have become second nature, media scholars easily lose sight of them. As a result, the special ontological status of the image as 'mediated' is easily overlooked and the technical make-up of the medium may simply go unquestioned - even by media scholars. In other words, media research does not necessarily benefit from the Sensitization Desensitization Cycles: long intervals of medium desensitization may straightforwardly facilitate a dominant research focus on the 'real' (an overlooking of the medium itself once habituation has kicked in). This may be referred to as the realist fallacy in media-historical research: desensitized to its effects, realists basically leave the medium itself understudied. Therefore, we must conclude that overlooking the medium is not 
an accidental, but a fundamental and structural phenomenon, also in the field of media research, and that habituation is the mechanism underlying the phenomenon (Van den Oever 2011; 2013).

\section{The re-sensitization of researchers}

Where does this leave media historians and their attempts to write the histories of media (technologies)? We assume that doing hands-on experiments with media technologies, e.g. in lab situations, helps to reverse the processes of habituation and de-sensitization. ${ }^{6}$ Such experiments help to re-sensitize researchers to the effects of media technologies (Fickers and Van den Oever 2014). Experimental media archaeology, hands-on, can make historians (at least potentially) aware of the material, technical and senso-perceptual make-up of old and obsolete media technologies and so-called 'dead' media (Hertz and Parikka 2012). As part of a cultural archaeology of (media) technology, such an enterprise seems relevant if not inevitable. As early cinema historian, Tom Gunning, argues in "Re-Newing Old Technologies", new technologies enter culture(s) charged with a utopian envisioning of a future they "radically transformed by the implications of the device or practice". However, he also concludes that the sinking of technology into "a reified second nature" indicates the failure, by and large, of the transformations envisioned: (once) new media end up fitting into, rather than changing, the already existing "grooves of power and exploitation". We need an archaeology of technology to grasp again the (lost) newness of old technologies as Gunning states $(2003,56)$.

On the basis of our own (lab) experiences with colleagues and students, we assume that in general researchers can be made much more medium aware and medium sensitive, not only to the old/dead media, but also to the traces their use left in historical reception documents, among them the cues marking distinct historical user experiences of media newness - mainly awe, wonder, and astonishment, in the perception of Gunning $(1995 ; 2003)$ : they provide an ideal background to the utopian envisionings in which the launch of novel media can take place. The re-sensitization of the researcher may make him/her more sensitive to the experiential, senso-perceptual and tacit dimensions of media use; moreover, it may help trigger questions concerning novelty experiences and their (mostly) sudden appearance and gradual disappearance as the ebb and flow of media's (de)habituation histories. ${ }^{7}$

\section{Hands-on experiments and reenactments as a research (and teaching) method}

One possible way of exploring past media practices is to do reenactments or handson experiments with old media devices, which is at the heart of a new approach called experimental media archaeology (Fickers and Van den Oever 2014). At the heart of this is our proposal to open the vaults and glass cases of museums: to make 
the device collections available to researchers for experiments, hands-on. ${ }^{8}$ Experimental media archaeology not only aims to sensitize researchers but, beyond that, to 'grasp' media and communication technologies in their concrete materiality and tangibility. Grasping is to be understood here as a hermeneutical act in the meaning given to it by Ernst Cassirer (1995): it comprises both the intellectual process of comprehending, as well as the sensory-bodily appropriation of getting a grip on things.

In line with Cassirer and others, we want to argue that doing media archaeological experiments in this experimental system of knowledge production turns historians into experimenters who experience the "mangle of practice" (Pickering 1995) of "science in action" (Latour and Woolgar 1979). From this experimental practice flows a series of advantages marked by researchers under a range of different labels: “collaborative thinking" (Corrigan 2012); "thinkering" (Huhtamo 2013); "heuristic groping" (Breidbach et al. 2010); or "bricolage" (Rheinberger 2015), taking place in a "living laboratory" (Arrigoni 2013), a context that fosters a process of "situated learning" (Lave and Wenger 1991) and "learning by doing" (Heering and Wittje 2001). Moreover, the careful documentation and self-reflexive analysis of such an experimental practice will be greatly beneficial for the fields of media archaeology, media history, and material and museum studies (Ludwig and Weber 2013; Byrne et al. 2011; Csikszentmihalyi 1993).

We wish to emphasize that doing experiments with old media technologies be it with originals or replicas - produces authentic contemporary experiences, but these (lab) experiences can, in no way, recreate 'authentic' historical experiences. As one of the pioneers of sensory history, Mark Smith, has convincingly argued, we need to carefully distinguish between sensory production and consumption. While it is possible to reproduce a particular sound or image of the past by using original hardware and software, the way we understand, experience and 'consume' these sounds and images is radically different from the way in which people interpreted these in the past. "Failure to distinguish between sensory production (something that can, at least theoretically, be replicated in the present) and sensory consumption (something that is hostage to the context in which it was produced) betrays the promise of sensory history", as Smith argued (2007, 841).

Doing hands-on experiments with old media technologies also opens up the way to a reflexive hermeneutical research practice aimed at reflections on the coconstructedness of situated knowledge production. Such a practice of reenacting, re-staging, re-doing, and re-making in an experimental setting is geared towards raising the awareness of the participants in the experiment about the functionalities ascribed to the materiality of the object (what can and cannot be done with a device), as well as the symbolic nature (design, semantics, interfaces). Moreover, such a practice facilitates the explication of implicit inventories of knowledge and ignorance (knowledge that provides a springboard for action); the creative disconcertion of available knowledge (education through failure); the reflective analysis of the per-formative dimension of technical objects (object as medium); and the 
critical reflections of the situational dynamics in the experimental space (between the object and the experimenter, as well as between different actors).

Although authenticity is "a currency and competency standard within the reenactor's history work", as Stephen Gapps (2009, 398) has put it, the reenactors/ experimenters are charmed not by the original, but by its authentic simulation. It is the combination of old and new, the playful practice of locating, embodying, and recalling that make reenactments or media archaeological experiments an authentic mode of communicative memory practices (Dreschke et al., 2016) or, to quote Tilmans, Van Vree and Winter (2010, 7): "Re-enactment is both affirmation and renewal. It entails addressing the old, but it also engenders something new, something we have never seen before. Herein lies the excitement of performance, as well as its surprises and its distortions". Reenactments and experimental approaches open up possibilities that allow history to be unfinished business (Gapps 2009, 207). With a similar appreciation, Simone Venturini (2013) speaks of a "handmade environment for using the technology available and the human and corporal reclaiming of the technology". Such 'aesthetic experimentations' with media devices are described by her as "practical operations on the technology and material of a reflective nature". Interestingly, in his 1977 book Ricognizione della semiotica, Emilio Garroni (quoted by Venturini 2013, 202) already typified such practical operations as mainly meta-operational activities.

While the heuristic potential of experimental media archaeology has been outlined in detail (Fickers and Van den Oever 2014; Fickers 2015; 2018), the question of how to document and 'translate' the sensorial experiences and perceptions made during such hands-on interactions with past media technologies remains largely unexplored. Within the field of 'sensory studies' (Howes 2013), anthropological and ethnographic approaches have been most explicit in documenting processes of embodiment and the plurality of sensory modes of engagement. Most prominently, Sarah Pink has advocated a 'sensory ethnography' that experiments with multiple media for the registration and communication of cultural facts and practices (Pink 2009). As a reflexive and experiential process through which understanding, knowing, and (academic) knowledge are produced, research on sensory perception and reception requires methods that are capable of grasping "the most profound type of knowledge [which] is not spoken of at all and thus inaccessible to ethnographic observation or interview" (Pink 2009, 4).

By using audiovisual media to document non-verbal communication, behaviour, and emotional reactions of users interacting with media technologies, we can try to open up for research and help make explicit the embodied and implicit forms of knowledge invested in past media usages. Sound and video recordings can work as analytical instruments to document the tacit knowledge of our hands, bodies, eyes, and ears when operating media devices; such recordings help us to grasp the complex and subtle human-machine relations as social interactions in situations of media consumption or use. In the exposure to the aesthetic and performative quality of media technologies, we aim to re-sensitize the experimental 
historians to their own embodiedness and enhance their awareness of the limitations of speech and written language as primary modes of knowledge production (Serres 2008). Capturing and documenting these embodied forms of implicit or tacit knowledge enables researchers to make explicit what the experimental historian of science Otto Sibum has described as "gestisches Wissen" - skilled knowledge (Sibum 1998, 154). Reflecting on his hands-on simulations of $16 \mathrm{~mm}$ film editing, John Ellis emphasized the limits of using linguistic/textual representations as the most adequate technique for describing implicit forms of expertise or technical skills: "Verbal analysis can go some way to explicating the details, but in the end this is hands-on history where information has to be experienced as well as written . . . or, at least, has to be read audiovisually" (Ellis 2015).

But what will such audiovisual representations tell us about the experiences of the experimenters/reenactors? Will they enable us to get closer to their sensorial perceptions, emotions or performative pleasures when interacting with old or replicated media technologies? Hardly so. Sure, a trained video or sound analyst (or experienced 'sensory ethnographer') might be able to detect specific gestures or emotional reactions, to map the spatial setting and situatedness of the human-machine interactions as well as the social interactions during the handson experiments that can help to qualify a reenactment as contemporary historical performance. However, in terms of interpretative evidence, such documentation remains somewhat speculative, unless used as a guide to our own encounters with these technologies. Much more important, it seems, is the added heuristic and metareflective value of doing hands-on experiments (and additionally document them audiovisually): to deconstruct the myth of authentic historical experience, moreover, to turn the inherent contradiction of any such endeavour into a purposefully distortive intellectual experience full of creative uncertainty.

\section{Epilogue: some remarks on authenticity, distortion, and the art of failure}

Instead of reproducing canonical master narratives of moments of 'media newness' based on discourse analysis of textual, sonic or visual representations of the past, the hands-on experiments with old media devices or replicas we propose aim, first of all, at re-sensitizing researchers and at the human and corporal reclaiming of technology (Venturini, 2013). It means a regaining of a keen, corporal sensitivity to the senso-perceptual, tacit, and experiential dimensions present in practices of media devices, a sensitivity researchers predictably lost in their routine use of media technologies. Second, we aim to nurture a heuristic and meta-reflective attitude towards user practices - including an awareness of the fact that making things work (as they should) is most likely to be an experience of failure, breakdown, and disappointment rather than one of immersion, habituation, and routinized pleasure. While our appropriation and use of media technologies - especially since the emergence of so-called consumer electronics since the 1960 s - can be 
negatively characterized by some as an 'inflation of things' ("Dinginflation”, Heßler, 2013), which have invaded our domestic and public spaces, the positive experience of some new media practices in the mechanical and electro-mechanical era, to some others, is the exposure to extensive intervals of tinkering, learning and, most importantly, repair and maintenance (Krebs, Schabacher and Weber 2018). In other words, habituation and routine use as dominant modes of media consumption are the result of a "ready to use" consumption habit (closely tied to a "ready to throw-away" culture in case of dysfunction), whereas the exposure to ever-new media invites de-habituation and a re-sensitization to (modes of) media use much appreciated by (new) media researchers.

Putting our hands, bodies, and brains to experiments with old media technologies will, inevitably, resensitize us to the fact that user manuals, do-it-yourself handbooks for operators, not to mention advertisements, have little to do with past or present realities of media usage. Just as the act of turning a messy and lengthy process of scientific experimentation into a publication must be interpreted as the first step in a process of canonization of knowledge (carefully subordinating the vitality of the experimentation process to a linear logic of reasoning and conceptual consistency; Rieß 1998), instruction books and leaflets accompanying media devices clearly represent idealized situations of use that have little in common with actual practices of appropriation and use.

For experimenters, the problem with experiments is that they rarely work according to plan, if they work at all. For historians, the problem with experiments is that scientists' accounts of them naturally reflect the plan or the finished product, rather than actual practice.

(Gooding 1989, 64)

What is true for experiments in science is certainly true for the less codified and structured spaces of experimental media archaeology. The "art of failure" (Aasman 2014) is probably one of the most important learning experiences in this heuristic practice. In his thought-provoking essay "Rethinking Repair", Steven Jackson (2014) pleas for a "broken world thinking" that focuses on moments of breakdown, maintenance, and repair instead of privileging moments of initial encounter and general predilections for the new. In re-orienting our attention to the history of "an aftermath, growing at the margins, breakpoints, and interstices of complex sociotechnical systems as they crack, flex, and bend their way through time" (ibid., 223), Jackson (ibid., 234) argues that we might be able to redirect our gaze from moments of production to moments of sustainability and "the myriad forms of activity by which the shape, standing, and meaning of objects in the world is produced and sustained - a feature especially valuable in a field too often occupied with the shock of the new". Building replicas, taking precious devices from their glass cases, and experimenting with originals will help to dehabituate media historians from their fixation on media newness and authenticity; to produce creative distortions in a field dominated by canonical narratives of technological inventions and innovations; to refocus on cascades of media use (rather than technical 
newness); and, lastly, to value the surprisingly capricious and quirky (de)habituation histories so typical of the experiences of past media practices.

\section{Notes}

1 As in our earlier articles written together, our names are presented in a simple alphabetical order. Fickers mainly contributed to the historiographical reflections; Van den Oever mainly contributed to the theoretical reflections. Here too, we draw from earlier, joint work (Fickers and Van den Oever 2014; 2018). Moreover, both of us draw from parts of our past research projects and publications; Van den Oever draws, in particular, from her work on distortions in the representation of figures leaping into the grotesque and the effects on viewers, published in Image E Text and in Leonardo in 2011 and 2013 respectively; and a research project she prepared with Ed Tan (in 2014) on sensitization desensitization cycles. Andreas Fickers builds on his research in the framework of the history of home movie film making (with Jo Wachelder, Susan Aasman, Tim van der Heijden and Tom Slootweg), stereophonic recording technologies (with Stefan Krebs) and transnational television transmissions (with Andy O'Dwyer).

2 Geoffrey Winthrop-Young is Kittler's most solid bridge between the German and Englishspeaking world. Winthrop-Young translated parts of Kittler's work, originally written in German, into English and wrote illusive introductions to his work, clarifying in passing Kittler's complex relations to Foucault, McLuhan, Arnheim, and others (see WinthropYoung 1999); with ironic precision, Winthrop-Young characterizes and clarifies Kittler's cryptic terminology and provocative phrasings (see Winthrop-Young 2011); see also our dialogue on Kittler and Arnheim (among other things): Winthrop-Young and Van den Oever 2014.

3 There are many examples (e.g., the amendments discussed by David Bordwell in his Poetics of Cinema from 2007), but in this article we mainly restrict ourselves to some references to Tsivian (1994), to be discussed below and in note 4 .

4 Remarkable examples have been excavated in an exemplary way by Yuri Tsivian in his illusive study of Early Cinema in Russia and Its Cultural Reception (1994). This study has inspired research in this field ever since. Today, many good examples are to be found in the phase of very early cinema and many particularly interesting discussions are to be found in the field of early cinema studies, a classic being the debates concerning Maxim Gorky's response to a Lumière "filmshow" in 1996: "Last Night I was in the Kingdom of Shadows"; for the full text, see: https://www.mcsweeneys.net/articles/ contest-winner-36-black-and-white-and-in-color.

5 Habituation is defined in standard studies as a dissipitation of a target-psychological response, e.g. psychophysiological activation at the presentation of a novel stimulus due to repeated exposure only; see Thompson and Spencer 1966.

6 In his 2003 article, Tom Gunning speaks of reversing the cycle of wonder.

7 There are signals that not all the novelty/arousal symptoms (fully) disappear due to habituation, for example, the question is whether the arousal effects triggered by the famously huge IMAX screens positioned above the seated cinema audience who is made to look up at them disappear: though the impact of the screens on experience is clearly designed by IMAX technicians to not fully disappear, the effects seem to be diminishing gradually. This is just one among many examples where further research is needed to explain the effects of habituation and user appreciation and acceptation (Van den Oever and Tan 2014).

8 For a range of examples and a further explication of the strategy, see also the "Introduction" by Fossati and Van den Oever to Exposing the Film Apparatus (2016, 13-43) and the examples provided by 29 authors in each of the successive 29 chapters. See also the historical, hands-on work done by BBC teams under the supervision of John Ellis and his research team studying the BBC television production practices of the 1960s: John Ellis, "16 mm Film Editing. Using Filmed Simulation as a Hands-on Approach to TV History", in: VIEW Journal of European Television History and Culture, 4(7); Available from: https:// vimeo.com/123212931 


\section{Andreas Fickers and Annie van den Oever}

\section{Bibliography}

Aasman, S. (2014) Staging the Amateur Film Dispositif. A Report. [Online]. Available from: https://homemoviesproject.wordpress.com/report-staging-the-amateur-dispositif/.

Ahrens, S. (2011) Experiment und Exploration. Bildung als experimentelle Form der Welterschließung. Bielefeld: Transcript.

Arrigoni, G. (2013) Innovation, Collaboration, Education: Histories and Perspectives on Living Labs. xCoAx 2013: Computation Communication Aesthetics and X, Bergamo.

Arnheim, R. (2004) Art and Visual Perception: A Psychology of the Creative Eye. Berkeley, CA: University of California Press.

Arnheim, R. (1977) Systematik der fruhen kinematographischen Erfindungen. In H. H. Dietrichs. (ed.). Kritiken und Aufsatze zum Film. Munich: Lizenzausg. der Ausg.

Arnheim, R. (2006) Film as Art. [Film als Kunst, 1932]. Berkeley, CA: University of California Press.

Balbi, G. (2015) Old and New Media. Theorizing Their Relationships in Media Historiography. In Kinnebrock, S., Schwarzenegger, C., and Birkener T. (eds). Theorien des Medienwandels. Köln: Halem, 231-249.

Bordwell, D. (2008) Poetics of Cinema. New York: Routledge/Taylor \& Francis Group.

Breidbach, O., Heering, P., Müller, M. and Weber, H. (2010) Experimentelle Wissenschaftsgeschichte. In Breidbach, O., Heering, P., Müller, M. and Weber, H. (eds). Experimentelle Wis-senschaftsgeschichte. Munich: Wilhelm Fink Verlag, 13-72.

Byrne, S., Clarke, A., Harrison, R. and Torrence, R. (eds) (2011) Unpacking the Collection: Networks of Material and Social Agency in the Museum. New York: One World Archaeology.

Cassirer, E. (1995) Form und Technik. In Orth, E. W. and Krois, J. M. (eds). Symbol, Technik, Sprache. Aufsätze aus den Jahren 1927-1933. Hamburg: Meiner, 39-89.

Chateau, D. and Moure, J. (2016) Screens: From Materiality to Spectatorship - A Historical and Theoretical Reassessment. Amsterdam: Amsterdam University Press.

Corrigan, K. (2012) Collaborative Thinking: The Challenge of the Modern University. Arts \& Humanities in Higher Education, 11(3): 262-72.

Csikszentmihalyi, M. (1993) Why We Need Things. In Lubar, S. and King-ery, W. D. (eds). History From Things: Essays on Material Culture. Washington/London: Smithsonian Institution Press, 20-29.

Dreschke, Anja et al. (eds) (2016) Reenactments: Medienpraktiken zwischen Wiederholung und kreativer Aneignung. Bielefeld: Transcript Verlag.

Edgerton, D. (2006) The Shock of the Old: Technology and Global History Since 1900. London: Profile Books.

Ellis, J. (2015) $16 \mathrm{~mm}$ Film Editing. Using Filmed Simulation as a Hands-on Approach to TV History. In VIEW Journal of European Television History and Culture, 4(7): 2015. [Online]. Available from: https://vimeo.com/123212931 (Accessed: 11 September 2018)

Fickers, A. and Van den Oever, A. (2014) Experimental Media Archaeology: A Plea for New Directions. In Van den Oever, A. (ed.). Technē/Technology. Amsterdam: Amsterdam University Press, 272-278.

Fickers, A. and Weber, A-K. (2015) Towards an Archaeology of Television. Editorial. VIEW Journal of European Television History and Culture, 4 (7). DOI: 10.18146/22130969.2015.jethc076.

Fickers, A. (2015) Hands-on. Plädoyer für eine experimentelle Medienarchäologie. Technikgeschichte, 82(1): 67-85.

Fickers, A. (2018) How to Grasp Historical Media Dispositifs in Practice. In Aasman, S., Fickers, A. and Wachelder, J. (eds). Materializing Memories. Dispositifs, Generations, Amateurs. New York: Bloomsbury, 85-91. 
Fickers, A. and Van den Oever, A. (2018) Doing Experimental Media Archaeology: Epistemological and Methodological Reflections on Experiments with Historical Objects of Media Technologies. In Roberts, B. and Goodall, M. (eds). New Media Archaeologies. Amsterdam: Amsterdam University Press, 45-68.

Fossati, G. and Van den Oever, A. (2016) Exposing the Film Apparatus. The Film Archive as a Research Lab. Amsterdam: Amsterdam University Press, 13-43.

Gapps, S. (2009) Mobile Monuments: A View of Historical Re-enactment and Authenticity from Inside the Costume Cupboard of History. Rethinking History, 13(3): 395-409.

Gitelman, L. (2008) Always Already New: Media, History, and the Data of Culture. Cambridge, MA: The MIT Press.

Garroni, E. (1977) Ricognizione della semiotica. Tre lezioni. Rome: Officina.

Gooding, D. (1989) History in the Laboratory: Can We Tell What Really Went On? In James, F. (ed.). The Development of the Laboratory. Essays on the Place of Experiment in Industrial Civilization. Basingstoke/London: Macmillan, 63-82.

Gunning, T. (1995) An Aesthetic of Astonishment: Early Film and the Incredulous Spectator. In Williams, L. (ed.). Viewing Positions: Ways of Seeing Film. New Brunswick, NJ: Rutgers University Press.

Gunning, T. (2003) Re-Newing Old Technologies: Astonishment, Second Nature, and the Uncanny in Technology from the Previous Turn-of-the-Century. In Thorburn, D. and Jenkins, H. (eds). Rethinking Media Change: The Aesthetics of Transition. Cambridge: MIT Press, 39-59.

Heering, P., Markert, M. and Weber, H. (eds) (2012) Experimentelle Wissenschafts-geschichte didaktisch nutzbar machen. Ideen, Überlegungen und Fallstudien. Flensburg: Flensburg University Press.

Heering, P. and Witje, R. (eds) (2011) Learning by Doing. Experiments and Instruments in the History of Science Teaching. Stuttgart: Franz Steiner Verlag.

Hertz, G. and Parikka, J. (2012) Zombie Media: Circuit Bending Media Archaeology into an Art. Leonardo, 45(5): 424-430.

Heßler, Martina (2013) Wegwerfen. Zum Wandel des Umgangs mit Dingen. Zeitschrift für Erziehungswissenschaft, 16(2), S. 253-266.

Howes, D. (2013) The Expanding Field of Sensory Studies. Version 1.0 (August 2013). [Online]. Available from: https://sensorystudies.org (Accessed: 8 September 2018)

Huhtamo, E. (2011) Thinkering with Media: On the Art of Paul DeMarinis. In DeMarinis, P. (ed.). Buried in Noise. Heidelberg: Kehrer, 33-39.

Huhtamo, E. (2013) Illusions in Motion. Media Archaeology of the Moving Panorama and Related Spectacles. Cambridge, MA: MIT Press.

Ihde, D. (1986) Experimental Phenomenology: An Introduction. New York: State University of New York Press.

Jackson, S. J. (2014) Rethinking Repair. In Gillespie, T., Boczkowski, P. and Foot, K. (eds). Media Technologies: Essays on Communication, Materiality and Society. Cambridge MA: MIT Press, 221-239.

Kittler, F. (1999) Gramophone, Film, Typewriter. Translated, with an Introduction, by Geoffrey Winthrop-Youg and Michael Wutz. Stanford, CA: Stanford University Press.

Krebs, S., Schabacher, G. and Weber, H. (eds) (2018) Kulturen des Reparierens. Bielefeld: Transcript.

Latour, B. and Woolgar, S. (1979) Laboratory Life: The Construction of Scientific Facts. Princeton, NJ: Princeton University Press.

Lawson, C. and Stowell, R. (1999) The Historical Performance of Music: An Introduction. Cambridge: Cambridge University Press.

Lave, J. and Wenger, E. (1991) Situated Learning: Legitimate Peripheral Participation. Cambridge: Cambridge University Press. 
Ludwig, D. and Weber, C. (2013) A Rediscovery of Scientific Collections as Material Heritage? The Case of University Collections in Germany. Studies in History and Philosophy of Science, Part A 44(4): 652-659.

Marvin, C. (1990) When Old Technologies Were New: Thinking About Electric Communication in the Late Nineteenth Century. Oxford: Oxford University Press.

Nerone, J. (2007) The Future of Communication History. Journal Critical Studies in Media Communication, 23(3): 259.

Nye, D. E. (2006) Technology Matters. Questions to Live With. Cambridge MA: MIT Press.

Park, D., Jankowski, N. and Jones, S. (2011) The Long History of New Media: Technology, Historiography, and Contextualizing Newness. [Online]. Available from: http://thelonghisto ryofnewmedia.net/toc/introduction-history-and-new-media (Accessed: 15 June 2018)

Peters, B. (2009) And Lead Us Not into Thinking the New is New: A Bibliographic Case for New Media History. New Media \& Society, 11(1/2): 13-30.

Pickering, A. (1995) The Mangle of Practice: Time, Agency, and Science. Chicago, IL: University of Chicago Press.

Pink, S. (2009) Doing Sensory Ethnography. London: Sage.

Rheinberger, H-J. (2015) Die Farben des Tastens. Hans-Jörg Rheinberger im Gespräch mit Alexandru Bulucz. Frankfurt am Main: Edition Faust.

Rieß, F. (1998) Erkenntnis durch Wiederholung - Eine Methode zur Geschichtsschreibung des Experiments. In James, F. (ed.). The Development of the Laboratory. Essays on the Place of Experiment in Industrial Civilization. Basingstoke/London: Macmillan, 157-172.

Salehabadi, D. (2016) The Scramble for Digital Waste in Berlin. In Oldenziel, R. and Trischler, H. (eds). Cycling and Recycling. Histories of Sustainable Practices. Berghahn: New York, 202-214.

Serres, M. (2008) The Five Senses. A Philosophy of Mingled Bodies. London: Continuum.

Sibum, O. (1998) Die Sprache der Instrumente. Eine Studie zur Praxis und Repräsentation des Experimentierens. In Heidelberger, M. and Steinle, F. (eds). Experimental Essays Versuche zum Experiment. Baden-Baden: Nomos, 141-156.

Smith, M. (2007) Producing Sense, Consuming Sense, Making Sense: Perils and Prospects for Sensory History. Journal of Social Sciences, 40(4): 841-858.

Thompson, R. F. Spencer, W. A. (1966) Habituation: A Model Phenomenon for the Study of Neuronal Substrates of Behavior. Psychological Review, 73: 16-43.

Tilmans, K., Van Vree, F. and Winter, J. (eds.) (2010) Performing the Past. Memory, History, and Identity in Modern Europe. Amsterdam: Amsterdam University Press.

Tsivian, Y. (1994) Early Cinema in Russia and Its Cultural Reception. Translated by Alan Bodger. Chicago, IL: University Press Chicago.

Turquety, B. (2014) Toward an Archaeology of the Cinema/Technology Relation: From Mechanization to 'Digital Cinema. Technē /Technology, 50-64.

Van den Oever, A. (2010) Ostrannenie, "The Montage of Attraction”, and Early Cinema's "Properly Irreducable Alien Quality". In Van den Oever, A. (ed.). Ostrannenie. On "Strangeness" and the Moving Image. The History, Reception, and Relevance of a Concept. The Key Debates. Mutations and Appropriations in European Film Studies, 1: 33-60.

Van den Oever, A. M. A. (2011) The Prominence of Grotesque Figures in Visual Culture Today. Rethinking the Ontological Status of the (Moving) Image from the Perspective of the Grotesque. Image \& Text, 18: 100-123.

Van den Oever, A. (2013) The Medium-Sensitive Experience and the Paradigmatic Experience of the Grotesque, 'Unnatural', or 'Monstrous'. Leonardo, 46(1): 88-89.

Van den Oever, A. and Tan, E. (2014) Settling the Unsettling: Medium Sensitization and Desensitization Cycles and the Adaptation to and Acceptation of Novel Media by Viewers. Project Proposal RUG/UvA 2014. 
Van den Oever, A. (ed.) (2014) "Introduction". In Van den Oever, A. (ed.). Technēf Technology. Researching Cinema and Media Technologies, Their Development, Use and Impact. The Key Debates. Mutations and Appropriations in European Film Studies, 4: $15-26$.

Venturini, S. (2013) Technological Platforms. In Hediger, V., Saba, C. G., Le Maitre, B. and Noordegraaf, J. (eds.). Preserving and Exhibiting Media Art. Challenges and Perspectives. Amsterdam: Amsterdam University Press, 201-202.

Wiesing, L. (2014) What are Media? Technē/Technology, 93-104.

Winthrop-Young, G. and Wutz, M. (1999) Translator's Introduction: Friedrich Kittler and Media Discourse Analysis. In Kittler, F. (ed.). Gramophone, Film, Typewriter. Translated, with an Introduction, by Winthrop-Young, G. and Wutz, M. Redwood City CA: Stanford University Press.

Winthrop-Young, G. (2011) Kittler and the Media. Cambridge: Polity.

Winthrop-Young, G. and Van den Oever, A. (2014) Rethinking the Materiality of Technical Media: Friedrich Kittler, Enfant Terrible with a Rejuvenating Effect on Parental Discipline, a Dialogue. Technē/Technology, 219-239. 